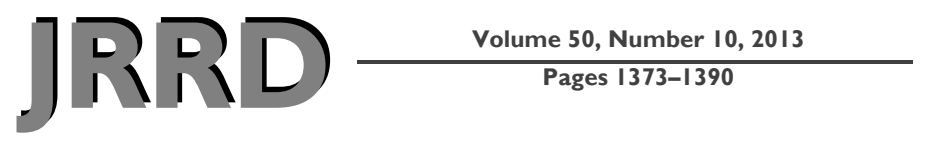

\title{
Evaluation of lightweight wheelchairs using ANSI/RESNA testing
} standards

\author{
Benjamin Gebrosky, BS; ${ }^{1}$ Jonathan Pearlman, PhD; ${ }^{1-2}$ Rory A. Cooper, PhD; ${ }^{1-4}{ }^{*}$ Rosemarie Cooper, MPT, \\ ATP; ${ }^{1-2,5}$ Annmarie Kelleher, MS, OTR/L, ATP ${ }^{1,5}$ \\ ${ }^{1}$ Human Engineering Research Laboratories, Department of Veterans Affairs (VA), Rehabilitation Research and Devel- \\ opment Service, VA Pittsburgh Healthcare System, Pittsburgh, PA; Departments of ${ }^{2}$ Rehabilitation Science and Tech- \\ nology, ${ }^{3}$ Bioengineering, and ${ }^{4}$ Physical Medicine and Rehabilitation, University of Pittsburgh, Pittsburgh, PA; ${ }^{5}$ Center \\ for Assistive Technology, University of Pittsburgh Medical Center, Pittsburgh, PA
}

\begin{abstract}
Lightweight wheelchairs are characterized by their low cost and limited range of adjustment. Our study evaluated three different folding lightweight wheelchair models using the American National Standards Institute/Rehabilitation Engineering Society of North America (ANSI/RESNA) standards to see whether quality had improved since the previous data were reported. On the basis of reports of increasing breakdown rates in the community, we hypothesized that the quality of these wheelchairs had declined. Seven of the nine wheelchairs tested failed to pass the multidrum test durability requirements. An average of 194,502 +/- 172,668 equivalent cycles was completed, which is similar to the previous test results and far below the 400,000 minimum required to pass the ANSI/ RESNA requirements. This was also significantly worse than the test results for aluminum ultralight folding wheelchairs. Overall, our results uncovered some disturbing issues with these wheelchairs and suggest that manufacturers should put more effort into this category to improve quality. To improve the durability of lightweight wheelchairs, we suggested that stronger regulations be developed that require wheelchairs to be tested by independent and certified test laboratories. We also proposed a wheelchair rating system based on the National Highway Transportation Safety Administration vehicle crash ratings to assist clinicians and end users when comparing the durability of different wheelchairs.
\end{abstract}

Key words: ANSI/RESNA, depot wheelchair, double drum, durability, fatigue tests, lightweight wheelchair, manual wheelchair, wheelchair, wheelchair comparison, wheelchair testing.

\section{INTRODUCTION}

Many factors must be considered when selecting a manual wheelchair. Based on good clinical practice as well as sound standards, clinicians recommend K0005, or ultralight wheelchairs (Table 1), because they allow for adjustable or selectable axle positions, camber, and seat angles, which are vital to a proper fit and optimal propulsion mechanics. This, in turn, helps to preserve upper limbs and reduce the risk of repetitive strain injuries (RSIs) in wheelchair users [1]. However, because ultralight wheelchairs cost more than less customizable ones, insurance providers often restrict their purchase. Thus,

\footnotetext{
Abbreviations: ANSI/RESNA = American National Standards Institute/Rehabilitation Engineering Society of North America, CDT = curb-drop test, CMS = Centers for Medicare and Medicaid Services, CAT $=$ Center for Assistive Technology, FDA = Food and Drug Administration, MDT = multidrum test, NHTSA = National Highway Transportation Safety Administration, RSI = repetitive strain injury, SD = standard deviation, VA = Department of Veterans Affairs.

*Address all correspondence to Rory A. Cooper, PhD; Human Engineering Research Laboratories (151R-B), VA Pittsburgh Healthcare System, 6425 Penn Ave, Suite 400, Pittsburgh, PA 15206; 412-822-3700; fax: 412-822-3699.

Email: rcooper@pitt.edu http://dx.doi.org/10.1682/JRRD.2012.08.0155
} 
ultralight wheelchairs are frequently denied for funding, despite their noted health and functional benefits. This often leaves a wheelchair user with a K0004, or lightweight wheelchair, as their only covered option.

Lightweight wheelchairs are typically designed with folding frames to decrease the overall width for storage or transport and with limited component adjustability and often do not allow adjustment of the rear axle location. While some lightweight wheelchairs do have adjustable axles, clinicians at the Center for Assistive Technology (CAT) in Pittsburgh, Pennsylvania, have stated that the range is usually not enough to have a large effect on the fit for a wheelchair user. If the wheelchair prescribed cannot be adjusted sufficiently to place the axle in the correct location for his or her body dimensions, it will negatively affect propulsion mechanics and, in turn, increase the risk of RSI, pain, and dysfunction in upper limbs, which may prematurely lead the wheelchair user to require a powered mobility device [3]. For long-term manual wheelchair users, this is particularly relevant.

The Food and Drug Administration (FDA) recommends using the American National Standards Institute/ Rehabilitation Engineering Society of North America (ANSI/RESNA) wheelchair testing standards to compare different wheelchair models [4]. Although wheelchair styles vary greatly, the ANSI/RESNA standards provide a way to characterize different models regardless of configuration. The ANSI/RESNA standards cover three domains: dimensions, stability, and durability or expected life. Accurate dimensions are essential for clinicians to ensure the wheelchairs they prescribe provide the best fit possible for a wheelchair user. Not all similarly classed wheelchairs are the same size, so a standard set of dimensions simplifies the process of selecting the correct model.

Stability testing results are helpful during the selection process, providing information about how the wheelchair performs on different inclines. Stability data also show the range over which a wheelchair remains stable when different components are adjusted to their limits. Knowledge of these limits is important to help minimize the risk of injuries, which are extremely common. Studies have shown that wheelchair users are susceptible to tipping over or falling out of their wheelchairs. Kirby et al. found that of 577 manual wheelchair users polled, 57.4 percent reported completely tipping over or falling out of their wheelchairs at least once [5]. A study by Xiang et al. found that $65-80$ percent of the injuries to wheelchair users from all age groups were caused by tips
Table 1.

"K" codes and their descriptions for common mechanical wheelchairs according to Healthcare Common Procedure Coding Scheme [2].

\begin{tabular}{|c|c|c|}
\hline Code & Description & $\begin{array}{r}\text { Features } \\
\end{array}$ \\
\hline$\overline{\mathrm{K} 0001}$ & $\begin{array}{l}\text { Standard } \\
\text { wheelchair }\end{array}$ & $\begin{array}{l}\text { No frame adjustments. } \\
\text { Approximate weight } 36 \mathrm{lb} \text {. } \\
\text { 19-21 in. seat-to-floor height. }\end{array}$ \\
\hline K0002 & $\begin{array}{l}\text { Standard hemi } \\
\text { (low seat) } \\
\text { wheelchair }\end{array}$ & $\begin{array}{l}\text { Same features and weight as K0001. } \\
\text { 17-18 in. seat-to-floor height. }\end{array}$ \\
\hline$\overline{\mathrm{K} 0003}$ & $\begin{array}{l}\text { Lightweight } \\
\text { wheelchair }\end{array}$ & $\begin{array}{l}\text { Few to no frame adjustments. } \\
\text { Weight }<36 \text { lb. } \\
\text { Standard seat width } 16-18 \text { in. } \\
\text { 19-21 in. seat-to-floor height. }\end{array}$ \\
\hline$\overline{\mathrm{K} 0004}$ & $\begin{array}{l}\text { High strength, } \\
\text { lightweight } \\
\text { wheelchair }\end{array}$ & $\begin{array}{l}\text { Minimal frame adjustments. } \\
\text { Standard seat width = 14-18 in. } \\
\text { Weight }<34 \text { lb. } \\
17-21 \text { in. seat-to-floor height. }\end{array}$ \\
\hline$\overline{\mathrm{K} 0005}$ & $\begin{array}{l}\text { Ultralightweight } \\
\text { wheelchair }\end{array}$ & $\begin{array}{l}\text { Frame adjustments common. } \\
\text { Seating adjustment common. } \\
\text { Highly adjustable axles. } \\
\text { Weight }<30 \text { lb. } \\
17-21 \text { in. seat-to-floor height. }\end{array}$ \\
\hline
\end{tabular}

and falls [6]. Furthermore, they reported that injuries due to wheelchair use are on the rise. Between 1991 and 2003, the number of wheelchair injures treated in U.S. emergency departments doubled. Wheelchairs with lower stability increase the likeliness of tipping over and falling out, and according to the data, these incidents and their resulting injuries are becoming more common.

Durability testing provides an estimate of the reliability and life expectancy of a wheelchair. Most insurance companies will only provide a replacement wheelchair every 3-5 yr. Wheelchairs that cannot meet this life expectancy may fail prematurely and be rendered useless or even injure the operator in extreme cases. An example of a major failure would be the deformation, fracture, or complete separation of a frame component that is integral to the functioning of the wheelchair. Even if a major failure does not occur, the failure of components such as the casters or seat fabric, for example, may render a wheelchair unusable until it can be brought in for service by a technician. One study found that component failures were second only to tips and falls as the leading cause of incidents interrupting normal wheelchair use, accounting for 33 percent of all the incidents recorded [7]. For manual wheelchairs, caster failures were the most common component failure in that study. Others have also characterized failures of wheelchairs in the community. Fitzgerald et al. polled 110 test subjects and discovered that 26 percent 
were required to perform some repair on their wheelchair over a 6 mo period [8]. Another article reported even worse reliability results. With a total of 2,213 subjects in their study, McClure et al. found that 44.8 percent of fulltime wheelchair users required repairs over a 6 mo period [9]. Most recently, an article by Worobey et al. reported failure rates of 52.6 percent from 726 subjects in the community [10]. The increasing rate of incidents, coupled with the time required to schedule and perform repairs, makes it clear that wheelchair reliability is getting worse and affects quality of life and safety.

When notifying the FDA that they intend to market their wheelchairs in the United States, manufacturers use the results of ANSI/RESNA testing as evidence that their wheelchairs are substantially similar to other devices on the market. Manual wheelchairs are placed in the class I medical device category, which allows the FDA to control their sale in the United States. This classification requires a premarket notification, or $510(\mathrm{k})$. A $510(\mathrm{k})$ submission requires performance testing, but there is no explicit minimum needed for approval. Without stated minimum requirements, a wheelchair may be approved for sale in the United States without passing the ANSI/ RESNA standard tests.

To obtain the proper coding for Centers for Medicare and Medicaid Services (CMS) reimbursement, there are some additional requirements, but they do not include ANSI/RESNA testing reports. The coding process is managed by Medicare Pricing, Data Analysis and Coding, who require test reports based on the ANSI/RESNA standards for powered wheelchairs and scooters when applying, but no such requirement currently exists for manual wheelchairs [11]. A few basic dimensions, maximum user weight, and a list of included accessories are the only items needed for the coding application. No performance requirements are necessary for a manual wheelchair to qualify for CMS reimbursement.

Compared to their ultralight counterparts, lightweight wheelchairs have typically performed poorly on the ANSI/RESNA standard tests [12-16]. Lightweight wheelchairs may trade some features for their lower cost, but this trade-off must not come at the expense of performance. A lower-cost wheelchair may require more frequent repairs or replacement, causing a wheelchair user to pay more money overall than with a model with a higher initial cost. Additionally, evaluations of lightweight wheelchairs indicated that they did not meet the minimum ANSI/RESNA standard test requirements for dura- bility [12]. In the $15 \mathrm{yr}$ since that study, several advances have been made that should have helped improve the quality of this style of wheelchair [17]. First, the widespread availability of computer-aided design and fatigue analysis software has made robust design more cost effective. Second, high-precision manufacturing methods, such as robot-guided welding and CNC (computer numerical control) machining, have become more readily available. These advances in design and manufacturing, along with the fact that the ANSI/RESNA durability standards have remained the same, should have resulted in higher quality, better durability, and cost-benefit. Nevertheless, as discussed earlier, wheelchair failures have been increasingly reported in the community over the last 15 yr [8-10].

In our study, we compared the performance of lightweight wheelchairs currently on the market to historically reported performance results. Additionally, the results of our lightweight wheelchair tests were compared with ultralight wheelchair test results from previous works. Finally, we proposed a rating system modeled after the National Highway Traffic Safety Administration (NHTSA) vehicle crash rating system to help determine the relative durability of a wheelchair when comparing different models.

Based on the trend of increasing wheelchair repairs in the community and the lack of regulation in the industry even though quality standards are available, we hypothesized that the durability of lightweight wheelchairs in a laboratory setting would decrease compared with historical data. Furthermore, we hypothesized that these current models would not meet the minimum requirements of the ANSI/RESNA standards with respect to durability testing and would be significantly less durable than ultralight wheelchairs based on the data from past studies.

\section{METHODS}

\section{Wheelchairs Tested}

Three samples of three different models for a total of nine wheelchairs were tested by using the methods specified in the 2009 edition of the ANSI/RESNA wheelchair standards [4]. This small sample size represents one of the limitations of this study. Wheelchair and testing costs were the driving factors for the number of samples tested. The wheelchairs selected (Figure 1) were the 9000XT (Invacare; Elyria, Ohio), Breezy 600 (Sunrise Medical; 


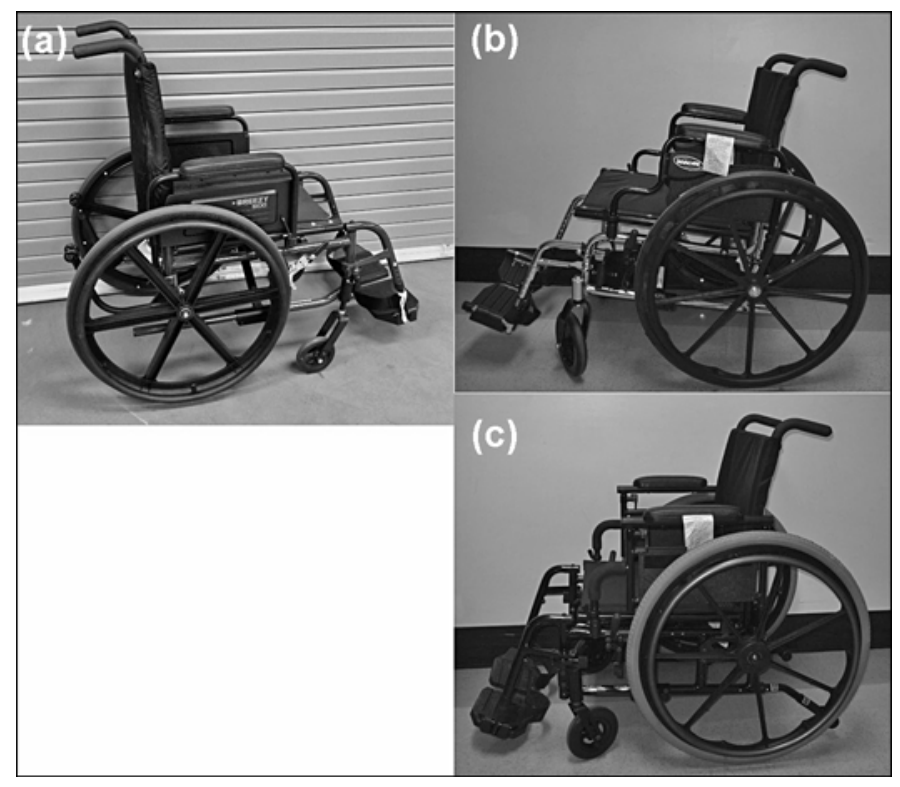

Figure 1.

Three wheelchair models tested in this study. (a) Sunrise Medical Breezy 600, (b) Invacare 9000XT, and (c) Invacare Patriot Plus.

Longmont, Colorado), and Patriot Plus (Invacare). We made these selections by polling clinicians at both the CAT and the Department of Veterans Affairs (VA) Pittsburgh Healthcare System wheelchair clinic about the wheelchairs they typically prescribed when a K0004 model was required. The Breezy 600 and Patriot Plus are constructed of aluminum, while the 9000XT is constructed of carbon steel. The wheelchairs were purchased during the same time period through a third party to ensure they were identical to commercially available models. All three models of wheelchairs are classed as K0004, or "high strength, lightweight wheelchairs," by the Healthcare Common Procedure Coding System and, except for the different frame materials, are of similar construction. The options selected during purchasing were chosen to ensure that the configuration of all three models was similar. All the samples had similar arm supports, foot supports, and seating systems to reduce variability in the results due to different options.

\section{Testing Procedure}

Six of the test sections specified in the ANSI/RESNA standards were completed on each wheelchair. They were as follows:

- Section 1: Determination of static stability.
- Section 3: Determination of effectiveness of brakes.

- Section 5: Determination of dimensions, mass, and maneuvering space.

- Section 7: Method of measurement of seating and wheel dimensions.

- Section 8: Requirements and test methods for static, impact, and fatigue strengths.

- Section 15: Requirements for information disclosure, documentation, and labeling.

After each section was completed, the wheelchairs were inspected for damage and items requiring repair were noted and corrected. Readjustment of items was completed as required by each individual test section. The only specification for testing order is found in section 8 , for which the tests must be performed in the order listed. In addition to this, because section 8 contains destructive tests, it was performed last. To maintain consistency, all the tests were performed in the same order for each wheelchair. The order in which the wheelchair specimens were tested was randomly selected by lottery and remained the same throughout the study. A test dummy that met the requirements of section 11 of the ANSI/ RESNA testing standards was used when necessary for all testing (Figure 2). The test dummy's mass was adjusted to $114.3 \mathrm{~kg}$ ( $250 \mathrm{lb}$ ), which is the maximum operator mass listed in each wheelchair's user manual. In addition to the durability requirements of section 8 , in order to determine ultimate fatigue life, we repeated the fatigue testing for every wheelchair that completed the minimum requirement until a failure that damaged a major wheelchair component (main frame, seat upright, etc.) was observed.

\section{Static Stability}

Static stability testing measures the angle at which a wheelchair will begin to tip when resting on an inclined slope. Each wheelchair was tested in the most stable and least stable configurations in the forward, rearward, and lateral directions according to section 1 of the ANSI/ RESNA standards. We configured the wheelchairs by adjusting different components (seat back angle, wheel horizontal location, etc.) to make them inherently more or less stable in the direction tipping would occur. Any antitipping devices shipped with the wheelchair were also tested. Furthermore, in the forward and rearward directions, the wheelchairs were tested with their rear wheels locked and unlocked. When testing the unlocked configuration, we placed the wheelchair up against a block to prevent the rear wheels from rolling. When testing with 


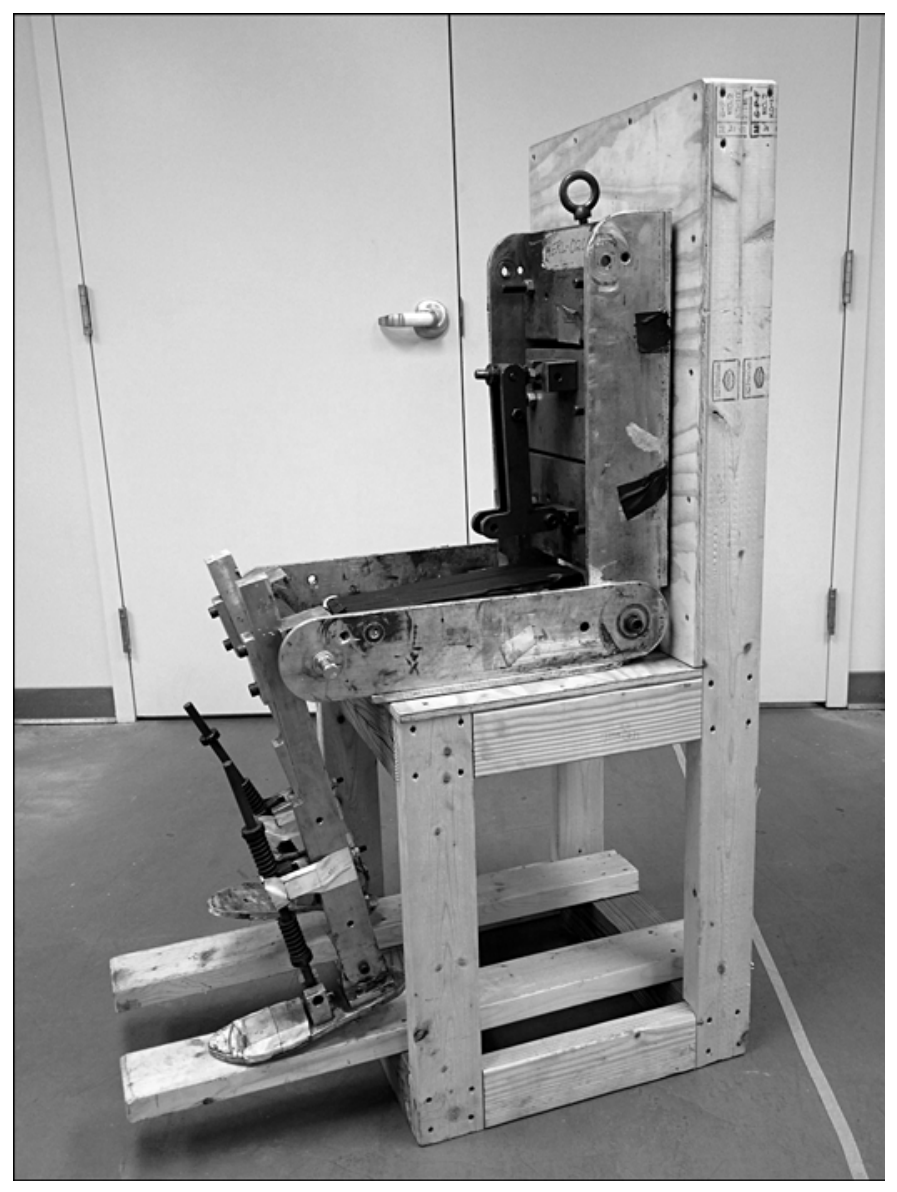

Figure 2.

Standard dummy used for testing (mass = $114.3 \mathrm{~kg}[250 \mathrm{lb}]$ ).

the wheels locked, we utilized the wheelchairs' own wheel locks to keep the wheels from turning and nylon straps were wrapped around the wheels to prohibit sliding when the incline angle was increased. The wheelchair was loaded with a test dummy and then placed on the test plane, which was able to incline from the horizontal position incrementally. Safety straps were attached to prevent the wheelchair from completely tipping over during testing but still allowed the chair to tip freely. The angle of the plane was then increased until the wheelchair began to tip. Tipping angles were determined by placing a sheet of paper under the uphill wheels and slowly increasing the angle of the test plane until the paper could slide out with little force (in accordance with ANSI/RESNA standards).

\section{Braking Effectiveness}

Braking effectiveness was tested using the methods in section 3 of the ANSI/RESNA standards. Each wheel- chair was prepared by adjusting the force required to operate its brake levers to $60 \pm 5 \mathrm{~N}$. The brakes were locked and the wheelchairs were secured along with the test dummy on the same horizontal plane used for static stability testing. The angle of the plane was increased until the wheelchair either began to slide downhill or its wheels began to turn. If the wheelchair began to tip before movement down the slope occurred, the test operator applied pressure perpendicular to the test plane to counteract the tip. This test was completed for each wheelchair twice: once facing uphill and again facing downhill.

\section{Static, Impact, and Fatigue Strength}

The tests specified in section 8 of the ANSI/RESNA wheelchair standards are designed to evaluate the durability of a wheelchair by testing various parts using situations similar to those seen in the real world. The tests are performed in order, and each wheelchair must pass every test to receive a passing score for the section.

Section 8 begins with static strength testing. The wheelchairs were placed on a test platform (Figure 3), and pneumatic actuators strategically mounted to the platform applied pressure to the arm supports, foot supports, antitip devices, hand grips, and push handles individually. The forces applied to each component depended on the mass of the wheelchair and the test dummy and were determined using formulae contained in ANSI/RESNA section 8. After each force application, the component tested was inspected to ensure it had not deformed or been affected in such a way that it no longer functioned as originally intended by the wheelchair manufacturer.

Impact testing was performed next. Each impact is designed to stress components of a wheelchair that may see impacts in daily use. An example impact would be the accidental contact of a handrim with a door frame while the user was traveling through the door. To pass this section, posttesting inspections must not show any breakage or damage that would affect normal wheelchair use.

A weighted pendulum was used to strike the back support, handrims, caster wheels, and foot supports. The back support impact tests used a pendulum consisting of a lead shot filled "regulation association football size 5" (soccer ball) with a mass of $25.0 \pm 0.5 \mathrm{~kg}$. The pendulum was adjusted so it was just touching the back support of the wheelchair when at rest. The pendulum was then raised $30^{\circ} \pm 2^{\circ}$ from vertical and released. All the wheelchairs in this comparison were designed with a back support consisting of fabric stretched between two 


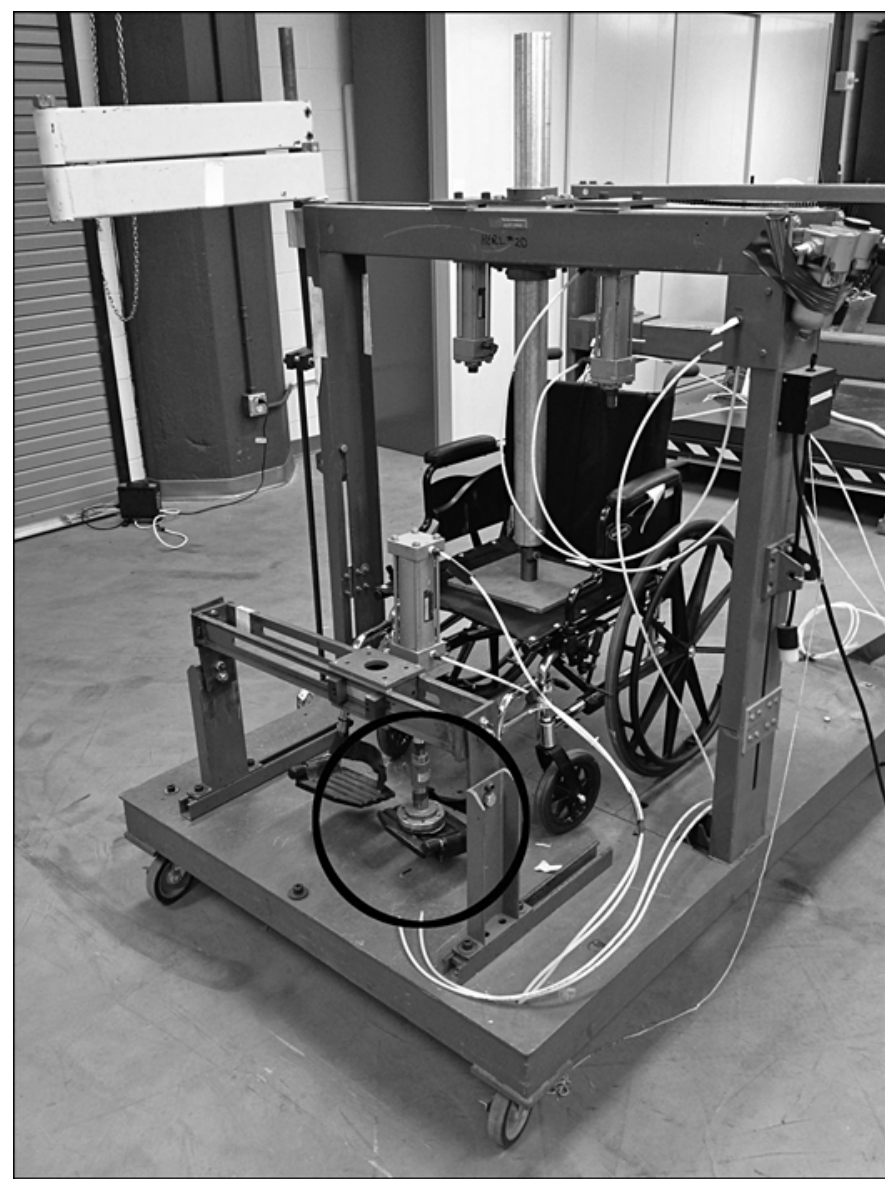

Figure 3.

Static wheelchair testing platform. Circled area shows footrest being tested in accordance with American National Standards Institute/Rehabilitation Engineering Society of North America standards.

support rods. In this special case, the standard required the pendulum to strike the center of the fabric once and to also strike each support rod once.

To impact the handrims, casters, and foot supports, a solid steel pendulum with a mass of $10 \mathrm{~kg}$ was used. For the handrims, the pendulum was raised $45^{\circ} \pm 2^{\circ}$ from vertical and released so that it struck the forward-most point on the handrim between two of the wheel rim attachment points. The pendulum swung parallel to the longitudinal axis of the wheelchair. The impact was repeated once on a different part of the same handrim also between two attachment points.

The casters and foot support tests used the same pendulum as the handrim test, but in this case, the angle from vertical was determined using a formula in the standard that considers the mass of the test dummy and wheelchair. The caster wheel was rotated $45^{\circ}$ from the longitudinal axis of the wheelchair for the impact test to provide a better contact surface for the pendulum. The footrest tests used the same formula as the caster test, but the impact was done in both the lateral and longitudinal directions.

Fatigue testing is the final portion of section 8 of the ANSI/RESNA standards to which wheelchairs are subjected. There are two parts to fatigue testing: the multidrum test (MDT) and the curb-drop test (CDT). The MDT has drums with $12 \mathrm{~mm}$-tall slats mounted to them that contact each wheel of the wheelchair once per revolution (Figure 4). The rear wheel roller is powered by an electric motor and rotates at $1.0 \pm 0.1 \mathrm{~m} / \mathrm{s}$. The front roller rotates 7 percent faster than the rear to vary the frequency at which the slats contact the wheels and randomize the roughness of the test. The test dummy was placed in the wheelchair and restrained to keep from falling out, but the restraints did not limit the natural movement of the dummy and the wheelchair. Each MDT test ran for 200,000 rotations of the rear roller. Periodic inspections were performed to see whether any wheelchair components had failed.

After completion of the MDT, we removed the wheelchair and attached it to the CDT machine via chains (Figure 5). Again, the test dummy was restrained so it could not fall out but was still able to move freely. The

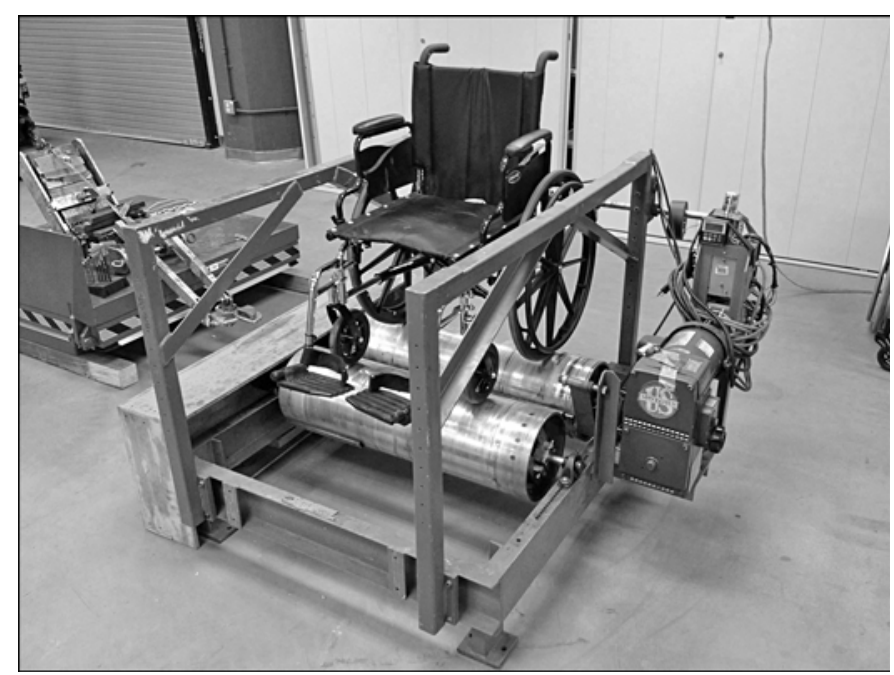

Figure 4.

Multidrum test machine (test dummy not installed). 


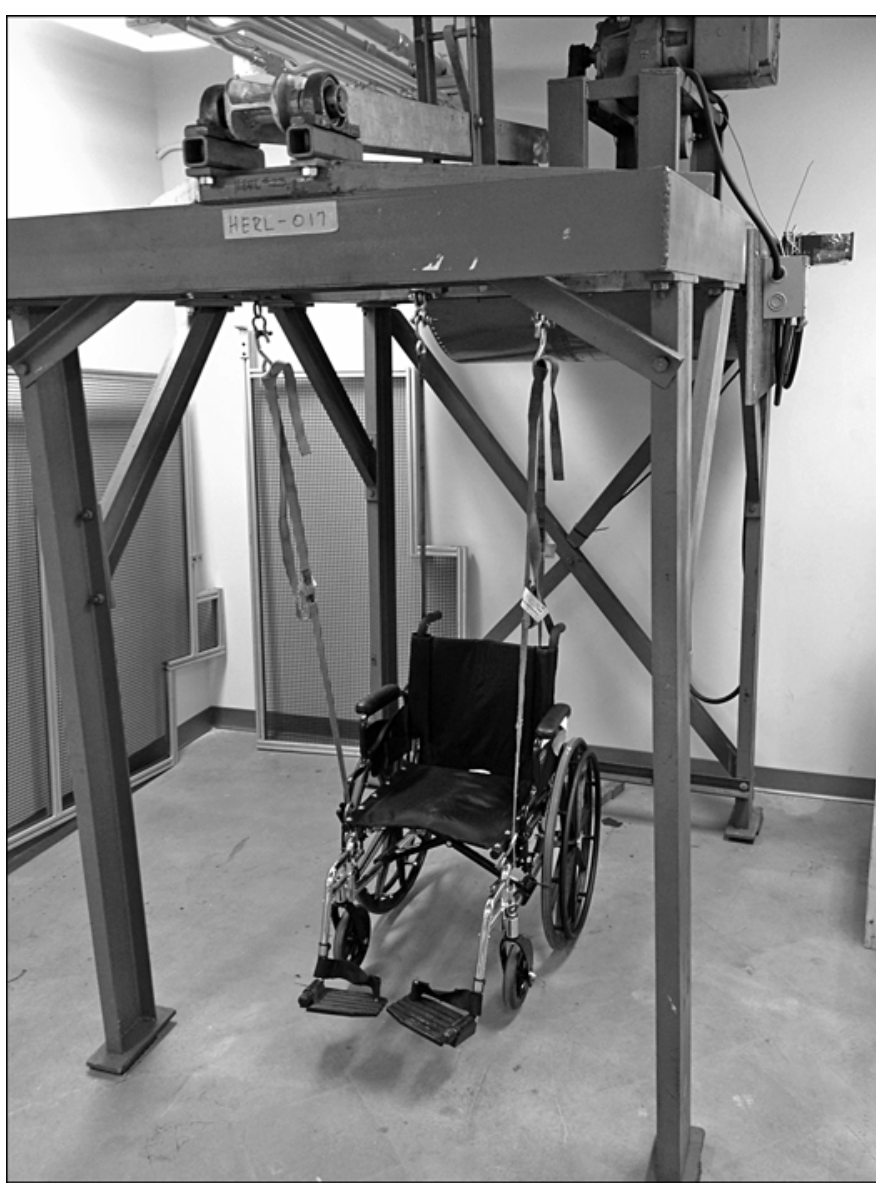

Figure 5.

Curb-drop test machine (test dummy not shown).

CDT machine was adjusted to raise each wheel of the wheelchair $50 \pm 5 \mathrm{~mm}$ from the ground plane. The machine then dropped the wheelchair in free fall back to the ground plane. This was repeated for a total of 6,666 cycles. The number 6,666 is taken directly from the ANSI/RESNA standards and is used so that each wheelchair will have completed 400,000 equivalent cycles at the conclusion of both fatigue tests. The formula for finding total equivalent cycles according to the ANSI/ RESNA standards is equivalent cycles $=30 \times \mathrm{CDT}$ cycles + MDT cycles.

Therefore, 6,666 CDT cycles equals 199,980 MDT cycles, which is approximated as 200,000. This equation was originally derived from the estimation that 1 CDT cycle is roughly equal to $30 \mathrm{MDT}$ cycles, although the origins of this equivalency are not documented. For this comparison study, once a wheelchair completed the 400,000 equivalent cycles, it was subjected to the MDT and CDT tests again in order until a catastrophic failure was recorded to determine the ultimate fatigue life of the wheelchair.

\section{Cost-Benefit}

An important factor to consider when selecting a wheelchair is the life cycle cost of the wheelchair. Wheelchairs that cost more but are more reliable may in fact cost the consumer and insurer less in the long run. To calculate the life cycle cost of each wheelchair, we divided the total equivalent cycles by the manufacturer's suggested retail price to arrive at a cycles per dollar figure. This provides a straightforward way for a wheelchair user or clinician to determine which wheelchair is more cost effective. Another factor affecting wheelchair cost is the number of repairs that must be performed over its lifetime. To characterize that, we recorded the time from the start of durability testing until the first failure that would require service by a technician occurred. Although this failure may not have rendered the wheelchair permanently useless, the time and cost of a service appointment can easily change the cost-benefit of a particular wheelchair.

\section{Data Analysis}

The primary results we were concerned with in this study were static stability, parking brake effectiveness, durability testing, and cost-benefit. A Kruskal-Wallis nonparametric analysis was used because of the small sample size and lack of normal distribution. The value for significance was set a priori at $p<0.05$. Where statistically significant results were found, a Mann-Whitney $U$ test was performed to determine which models were different in the group. Additionally, a Kaplan-Meier survival analysis was completed to compare the equivalent cycles from fatigue testing to previously published comparison studies [12-16].

\section{RESULTS}

\section{Dimensions}

All the wheelchairs tested were equipped with solid tires from the manufacturer. The 9000XT and Patriot Plus wheelchairs were supplied with $610 \mathrm{~mm}$ main wheels, and the Breezy 600 used $580 \mathrm{~mm}$ wheels. Other important dimensions are listed in Table 2. 
Table 2.

Mean dimensions of Quickie Breezy 600 and Invacare Patriot Plus and 9000XT wheelchairs in this study.

\begin{tabular}{lccc}
\hline & Quickie Breezy 600 & Invacare Patriot Plus & Invacare 9000XT \\
\hline Length (mm) & 990 & 1,077 & 1,087 \\
Width (mm) & 650 & 672 & 650 \\
Handgrip Height (mm) & 945 & 878 & 913 \\
Mass (kg) & 15.6 & 17.6 & 15.9 \\
Minimum Turning Diameter (mm) & 1,620 & 1,553 & 1,683 \\
Minimum Pivot Width (mm) & 1,257 & 1,247 & 1,333 \\
\hline \hline
\end{tabular}

\section{Static Stability}

Static stability results for the models in this study can be found in Table 3. Statistically significant differences were found for some sections and are noted as such in the table. Of the three models tested, the Patriot Plus recorded the highest stability in most, followed by the 9000XT, which scored second highest overall. The Breezy 600 was the least stable of the three and did not receive a high score in any of the tests.

\section{Braking Effectiveness}

The results of the braking effectiveness tests are shown in Table 4. During this test, the wheels of all nine wheelchairs turned in both the forward and rearward directions, meaning that the brakes were the limiting factor of stopping ability according to the methods in the standard. In previous studies [12-16], the wheelchairs were allowed to tip if the incline increased to the tipping point before the brakes were overpowered or the wheels slid. The angle of tip was considered the maximum brake effectiveness number in that direction. The current ANSI/ RESNA standards require the test operator to apply a force normal to the test plane onto the wheelchair in order to eliminate this tipping and provide a theoretical brake or wheel slip angle. Previous versions of the standards did not include this requirement. Statistically significant results were found for the facing uphill tests, where the Breezy 600 and Patriot Plus scored the highest.

\section{Strength and Durability Testing}

Every wheelchair in this study passed the static and impact test parts of this section, but not all passed the MDT and CDT. Table 5 shows the failures for each wheelchair and the number of equivalent cycles that had elapsed when the failure occurred. For the purposes of this study, noncritical failures are incidents that would require the wheelchair user to perform a repair or have someone complete an in-home service call. Critical failures require the replacement of wheelchair components, such as the main frame or seat frame, that are required for operation. A critical failure would require the user to bring the wheelchair to a sales office or repair shop for service. The classification of a critical versus noncritical failure has no relationship to the hazards present to the user when a failure occurs; all the noncritical failures in our study could potentially cause serious injuries if they occur during use. The

Table 3.

Static stability results.

\begin{tabular}{|c|c|c|c|c|c|c|c|c|}
\hline & \multicolumn{8}{|c|}{ Condition } \\
\hline & \multicolumn{2}{|c|}{$\begin{array}{c}\text { Forward Unlocked } \\
\text { Test Section/Stability }\end{array}$} & \multicolumn{2}{|c|}{$\begin{array}{c}\text { Rearward Locked } \\
\text { Test Section/Stability }\end{array}$} & \multicolumn{2}{|c|}{$\begin{array}{c}\text { Rearward Unlocked } \\
\text { Test Section/Stability }\end{array}$} & $\begin{array}{c}\text { Left Lateral } \\
\text { Test Section/Stability }\end{array}$ & $\begin{array}{c}\text { Right Lateral } \\
\text { Test Section/Stability }\end{array}$ \\
\hline & 9.2/Least & 9.4/Most & 10.3/Least & 10.5/Most & 10.2/Least & 10.4/Most & 12.1/Least $\quad 12.2 /$ Most & 12.1/Least $\quad 12.2 /$ Most \\
\hline Mean \pm SD & $28.3 \pm 0.78_{a}$ & $35.2 \pm 0.25$ & $5.5 \pm 0.22_{a}$ & $5.8 \pm 0.29_{a}$ & $11.2 \pm 1.28$ & $11.3 \pm 1.28_{\mathrm{a}}$ & $17.6 \pm 0.81_{\mathrm{a}} \quad 17.1 \pm 0.99$ & $17.9 \pm 1.38_{a} \quad 17.6 \pm 0.84_{a}$ \\
\hline Range & \multicolumn{2}{|c|}{$6.9 \pm 0.66$} & \multicolumn{2}{|c|}{$0.3 \pm 0.08$} & \multicolumn{2}{|c|}{$0.1 \pm 0.37$} & $-0.5 \pm 0.21$ & $-0.3 \pm 0.57$ \\
\hline $\begin{array}{l}\text { Patriot Plus } \\
\end{array}$ & & & & & & & & \\
\hline$\overline{9000 X T}$ & & & & & & & & \\
\hline Mean \pm SD & $32.2 \pm 0.4_{\mathrm{C}}$ & $40.1 \pm 0.2$ & $8.2 \pm 0.1_{\mathrm{c}}$ & $8.3 \pm 0.1_{\mathrm{c}}$ & $15.8 \pm 1.0$ & $16.2 \pm 1.2_{\mathrm{c}}$ & $22.6 \pm 0.6_{c}$ & $22.3 \pm 1.5_{c}$ \\
\hline Range & \multicolumn{2}{|c|}{$7.9 \pm 0.5$} & \multicolumn{2}{|c|}{$0.1 \pm 0.1$} & \multicolumn{2}{|c|}{$0.3 \pm 0.3$} & $3.8 \pm 0.7$ & $4.0 \pm 1.9$ \\
\hline
\end{tabular}


Table 4.

Braking effectiveness results (mean \pm standard deviation).

\begin{tabular}{lrc}
\hline & \multicolumn{2}{c}{ Tip Angle ( ${ }^{\circ}$ ) } \\
\cline { 2 - 3 } & Downhill & Uphill \\
\hline Sunrise Medical Breezy 600 & $12.1 \pm 1.1$ & $18.6 \pm 5.5^{\mathrm{a}}$ \\
Invacare Patriot Plus & $13.2 \pm 2.3$ & $15.4 \pm 0.4^{\mathrm{a}}$ \\
Invacare 9000XT & $9.2 \pm 1.3$ & $11.5 \pm 0.7^{\mathrm{b}}$ \\
\hline a,b denote significantly different groups. & & \\
\hline
\end{tabular}

durability requirements in this study are similar to those found in the ANSI/RESNA standards, with a few key differences. The ANSI/RESNA requirements allow for tires, inner tubes, and caster wheel rubber to be replaced one time each during the durability tests. One of the nine wheelchairs we tested had a tire failure, which was replaced and the testing continued. Additionally, "operator-adjustable components" may be retightened, readjusted, or refitted at 25 percent intervals throughout the durability tests. If the components require special tools for retightening, etc., the tools must be provided with the wheelchair. Finally, the standards state that "no component shall be fractured or become detached." This means that every noncritical failure recorded in this study would fail the durability requirements of ANSI/RESNA. Because the noncritical failures could be repaired either by the user or a service technician, we repaired the damage and continued testing until a failure that required the replacement of a major component was encountered. Figure 6 shows a graphical view of the equivalent cycles each wheelchair completed before failure on the fatigue tests. A line was included in the figure to show which wheelchairs met the minimum requirements according to the ANSI/RESNA standards. No significant differences were seen in the equivalent cycle results. The Breezy 600 had the highest mean equivalent cycles and the Patriot Plus survived the fewest. The Breezy 600 was also the only wheelchair model to complete 200,000 cycles on the double drum and the 400,000 minimum equivalent cycles for both fatigue tests. Two of the three Breezy 600 wheelchairs accomplished this.

\section{Critical Failures During Durability Testing}

\section{Sunrise Medical Breezy 600}

All three Breezy 600 wheelchairs had critical failures of the main frame during MDTs (Figure 7). Two of three devices suffered failures near the caster barrel in the heataffected zone of the welds. The other device failed at the lower rear frame section near the vertical member, also in a heat-affected zone. Two of the three failures occurred on the second round of double-drum testing, after completing the initial 200,000 multidrum and 6,666 curb-drop cycles.

None of the Patriot Plus wheelchairs tested survived the required 200,000 cycles on the MDT. Each wheelchair failed in the same manner, with a rear back support upright fracturing and separating from the frame in the heat-affected zone where it was welded to the main frame (Figure 8).

\section{Invacare 9000XT}

Only one of the three 9000XT models completed the required 200,000 cycles of the MDT. Upon inspection,

Table 5.

Noncritical and critical failures in this study.

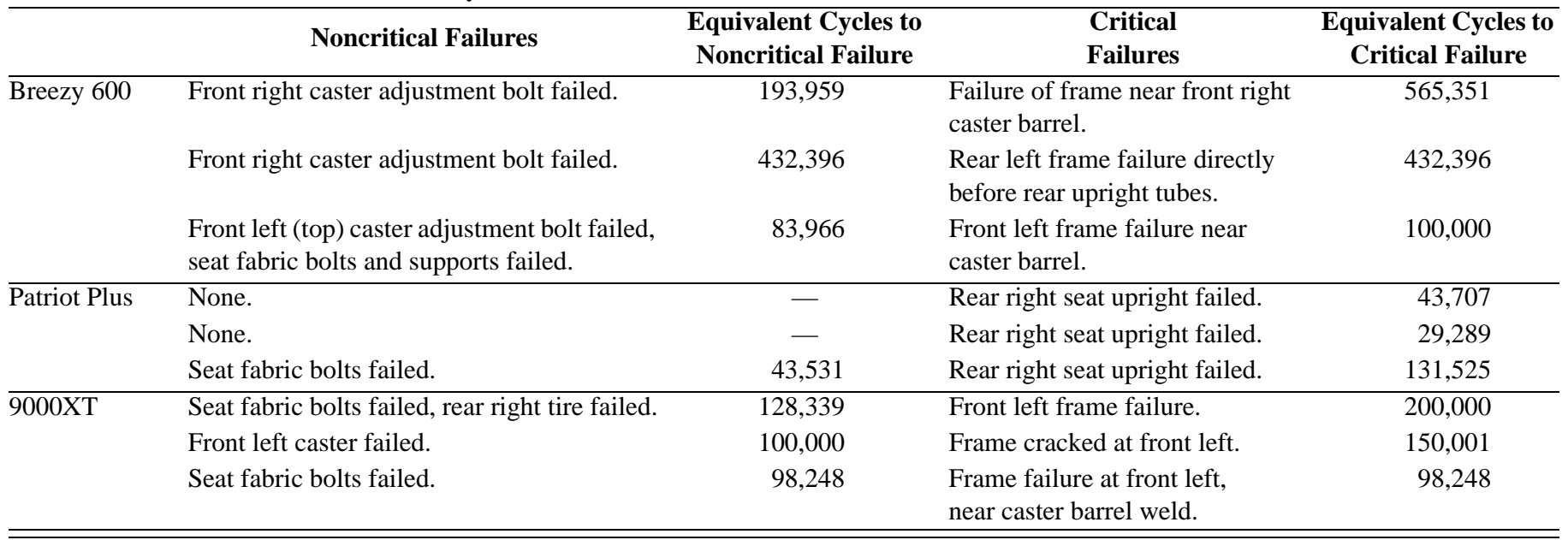




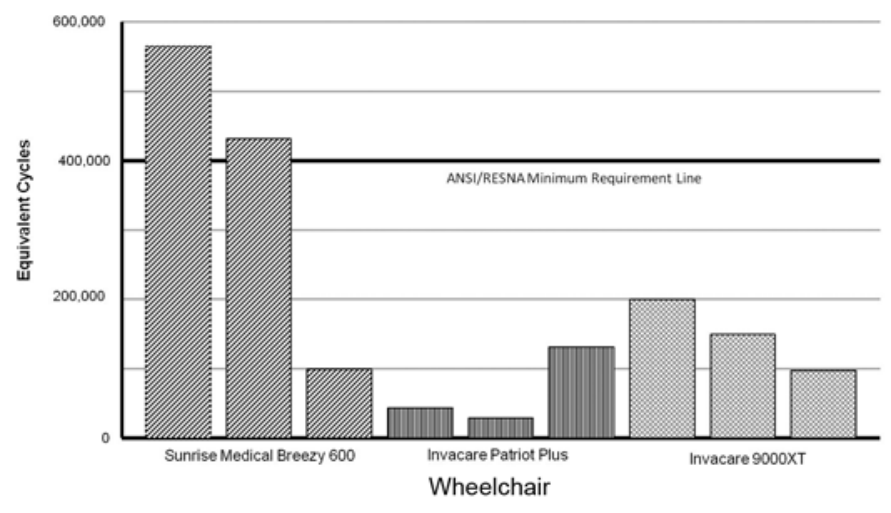

Figure 6.

Equivalent cycles of wheelchairs in this study. ANSI/RESNA = American National Standards Institute/Rehabilitation Engineering Society of North America.

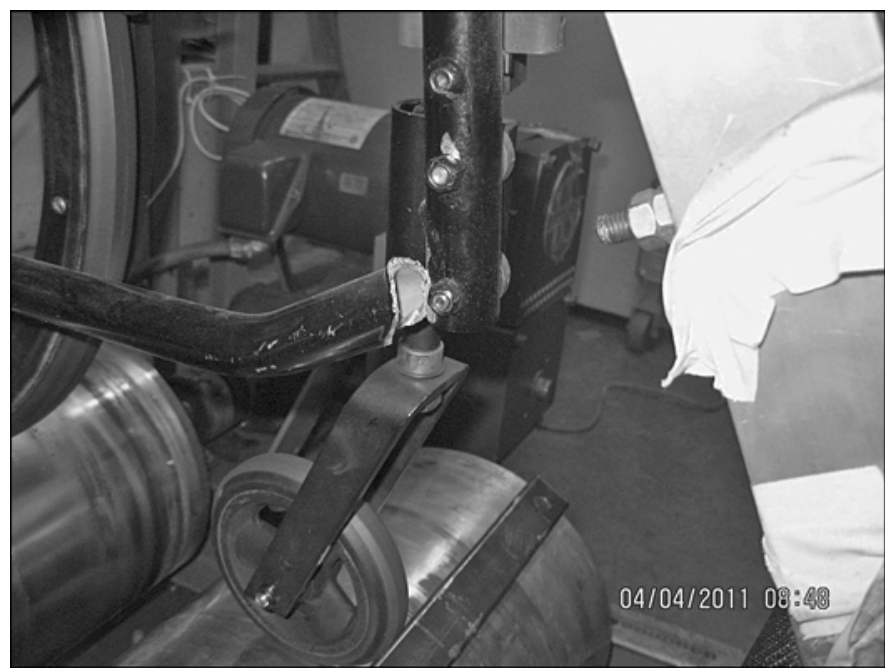

Figure 7.

Failure of front-left main frame on Sunrise Medical Breezy 600 wheelchair.

we discovered that the frame had failed near the caster barrel sometime between the last inspection and the completion of the MDT but did not separate enough to trip the safety switches on the test machine and stop the testing. Although the chair had completed the required cycles, because of this failure, it was unable to begin the CDT. Corrosion was discovered inside the frame tubing after the failures (Figure 9). All three wheelchairs exhibited this corrosion, suggesting that it was either present

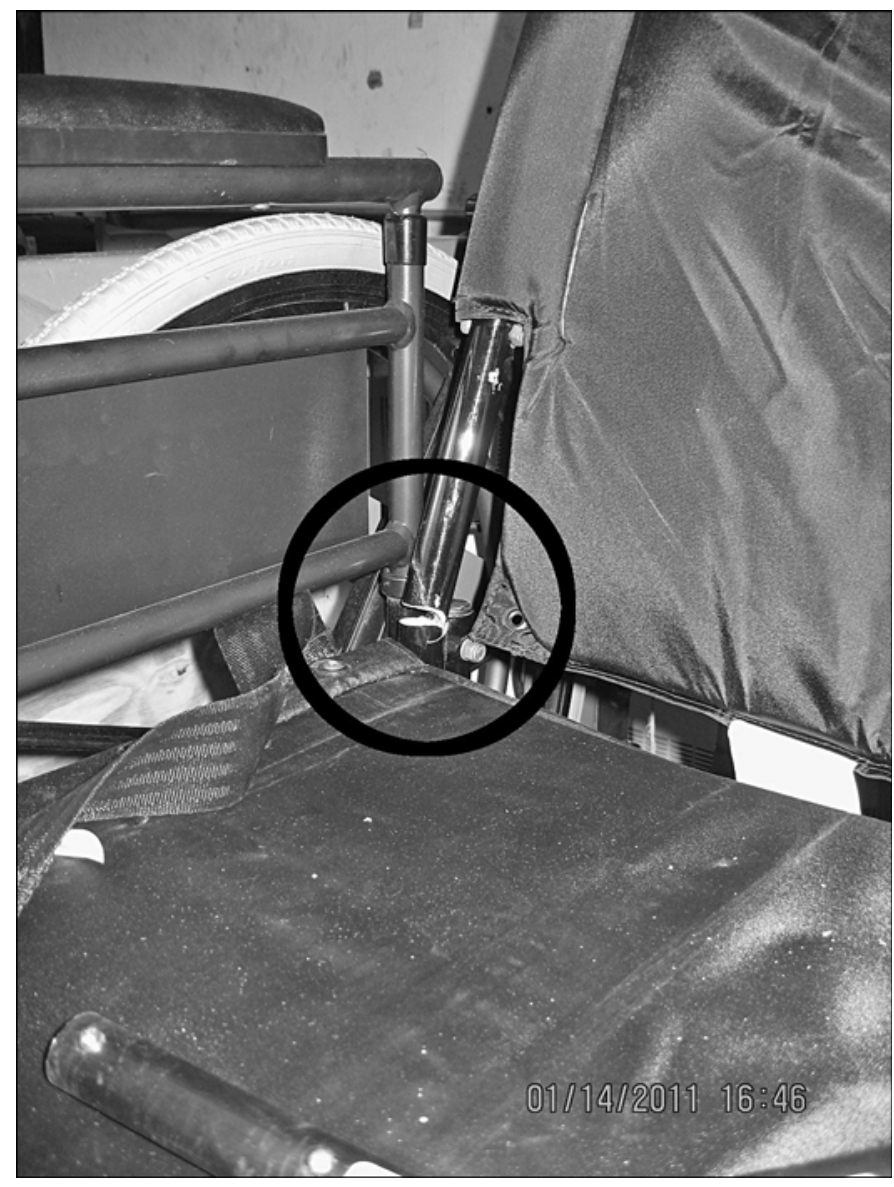

Figure 8.

Invacare Patriot Plus seat upright failure.

before construction or that a design flaw existed that allowed the corrosion to develop later on.

\section{Cost-Benefit}

The cost-benefit of a wheelchair can be useful information when considering different models and styles. Table 6 shows the cost-benefit in cycles per U.S. dollar for each model tested in this study. Statistical analysis did not show any significant differences in the results between the wheelchairs tested.

\section{DISCUSSION}

\section{Static Stability and Braking Effectiveness}

The minimum value used in the determination of stability is $7^{\circ}$. This represents the absolute maximum permissible slope of a ramp (with a rise of 3 in. or less) 
Table 6.

Cost-benefit results for this study and previous lightweight folding wheelchairs study (LWFW I) [12].

\begin{tabular}{|c|c|c|c|}
\hline Wheelchair & $\begin{array}{c}\text { Suggested Retail Price } \\
(\$) \\
\end{array}$ & $\begin{array}{c}\text { Equivalent Cycles } \\
(\text { Mean } \pm \text { SD) }\end{array}$ & $\begin{array}{c}\text { Cycles } / \$ \\
(\text { Mean } \pm \text { SD) }\end{array}$ \\
\hline Sunrise Medical Breezy 600 & & $365,916 \pm 195,708$ & $334 \pm 179$ \\
\hline Invacare Patriot Plus & & $68,174 \pm 45,181$ & $69 \pm 46$ \\
\hline Invacare 9000XT & & $149,416 \pm 41,542$ & $149 \pm 41$ \\
\hline \multicolumn{4}{|l|}{ LWFW I ${ }^{*}$} \\
\hline Quickie Breezy & & $232,453 \pm 45,895$ & $233 \pm 46$ \\
\hline
\end{tabular}

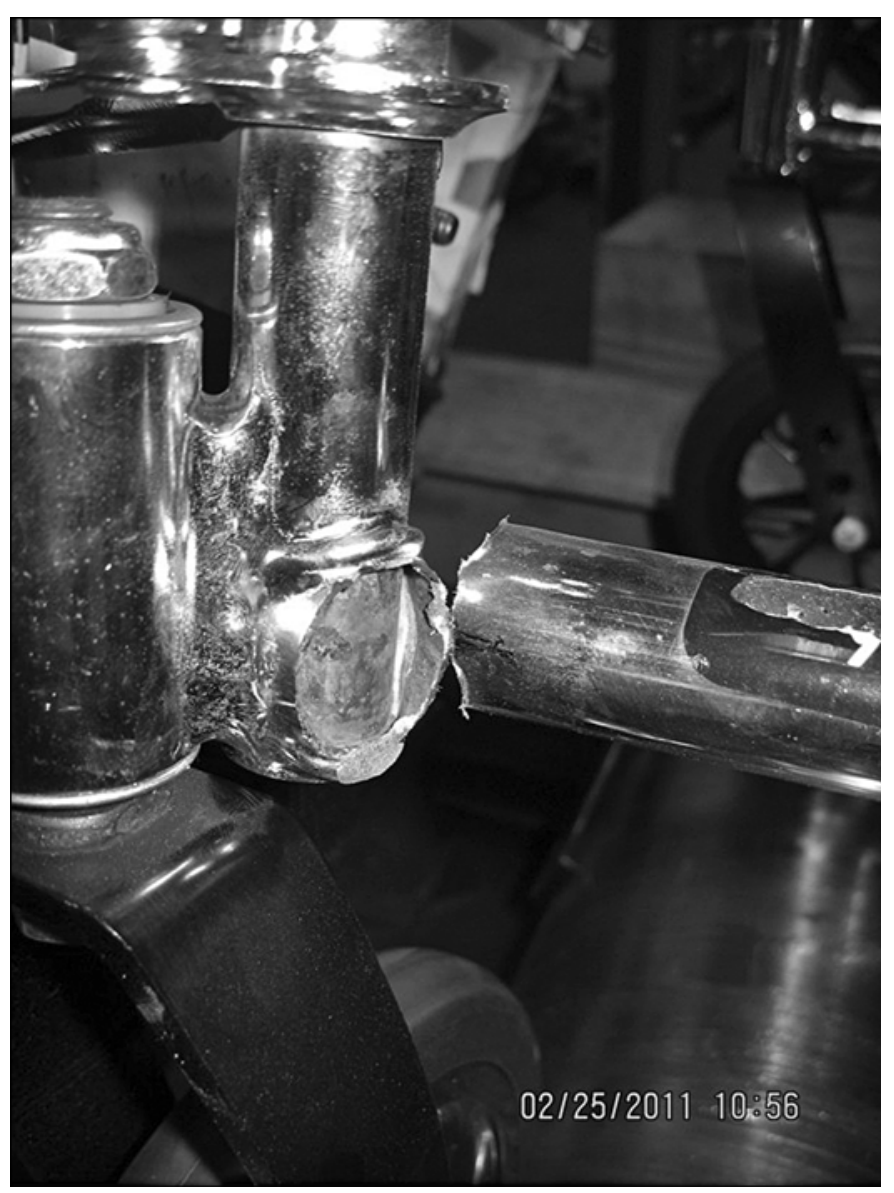

Figure 9.

Corrosion found inside tubing of Invacare 9000XT wheelchairs immediately following failure.

according to the Americans with Disabilities Act Accessibility Guidelines for existing buildings and facilities
[18]. Although higher slopes that are not ramps can be found in the community, a $7^{\circ}$ slope is something a wheelchair user may encounter on a regular basis. Both the Invacare Patriot Plus and Invacare 9000XT were able to meet this minimum regardless of configuration. The Sunrise Medical Breezy 600, however, tipped when facing uphill on an incline with its rear wheels locked before the $7^{\circ}$ value was reached. This could lead to a dangerous situation; with the rear wheels locked facing uphill, users can do little to keep from tipping other than shifting their weight forward quickly, which may be difficult or impossible for someone with limited mobility. These types of tips are particularly common for manual wheelchair users; Gaal et al. reported that 50 percent of the tips and falls in their study for manual wheelchair users were in the rearward direction [7]. While the total number of injuries requiring medical attention was less than in the forward direction (13 forward vs 7 rearward), five of those rearward tip cases required hospitalization, while only two of the forward tipping incidents resulted in hospital stays. One way to decrease the risk of tipping over in the Breezy 600 would be to install antitip wheels. While they will not prevent all tips, antitip wheels will greatly limit the risk of a tip over in the rear direction. Braking effectiveness results were also encouraging. Two of the three wheelchair models were able to remain stable, and all three models remained immobile on a $7^{\circ}$ slope. Additionally, the static stability results showed that the Patriot Plus and 9000XT wheelchairs would not tip even in their least stable configuration at this incline. Although the Breezy 600 scored well over the $7^{\circ}$ minimum in the facing uphill braking test, because of its static stability results, it would have tipped before the brakes slipped. The braking results are similar in the downhill 
direction to those reported in the previous lightweight wheelchair study [12]. Results from our study and the previous one are shown in Table 7. The facing downhill results are essentially the same for both studies. The higher values recorded in the facing uphill direction for our study can likely be attributed to the new test methods discussed earlier.

\section{Strength and Durability}

Of the nine wheelchairs tested, only two survived the 400,000 equivalent cycles necessary to pass section 8 of the ANSI/RESNA testing standards. The mean \pm standard deviation (SD) equivalent cycles for the wheelchairs in this study was $194,502 \pm 172,668$, which is slightly less than the minimum number of cycles required to pass the MDT. These results are very similar to those from the previous lightweight wheelchair study, which found a mean of 187,326 $\pm 144,302$ cycles before failure [12] This suggests that the durability of the frame of lightweight wheelchairs has remained unchanged over the past 15 yr. Considering that neither group on average survived long enough to complete the double drum testinglet alone the minimum durability requirements-this is cause for concern. Failure locations varied overall (Figure 10); however, every critical failure was located in or around the heat-affected zones of welded joints. This indicates that the design of the wheelchair, the fabrication process, or a combination of both may have limited frame durability. We used the equivalent cycle results from previous studies to determine how the latest lightweight wheelchair models fared in comparison [12-16], and a Kaplan-Meier plot was created to graphically show the differences (Figure 11). Table 8 highlights some of the different critical failures found in this study and the possible outcomes that might occur as a result.

\section{Table 7.}

Braking effectiveness results (mean \pm standard deviation) for previous lightweight folding wheelchairs study (LWFW I) [12] and current study.

\begin{tabular}{cc}
$\begin{array}{c}\text { Facing Downhill } \\
\left({ }^{\circ}\right)\end{array}$ & $\begin{array}{c}\text { Facing Uphill } \\
\left.\mathbf{(}^{\circ}\right)\end{array}$ \\
\hline $11.2 \pm 1.0$ & $12 \pm 1.2$ \\
$11.5 \pm 2.3$ & $15.2 \pm 4.3$ \\
\hline
\end{tabular}

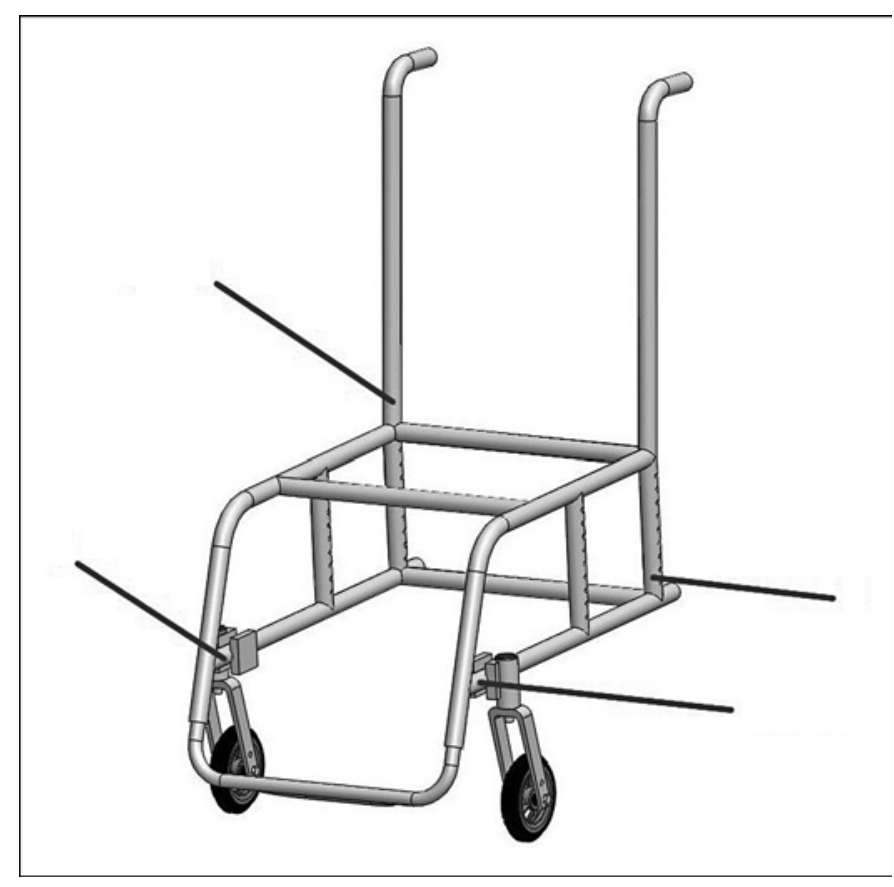

Figure 10.

Locations of critical failures on wheelchairs in this study. (Rear wheels and seating system not shown.)

\section{Failure Analysis}

\section{Sunrise Medical Breezy 600}

Although the Breezy 600 wheelchairs survived the longest during the durability tests, the critical failures encountered represent a weakness in the frame that appears to be a fault of the design. Although all three wheelchairs failed near welded joints, no direct evidence pointed to the welding process as the reason for the failures. The frame failed in the heat-affected zone in all cases, which is the weakest region in a welded member [19]. This indicates that the joints were not designed to handle the forces that are present with a full-weight test dummy. Since two of the wheelchairs failed in the lower frame tube near the front caster attachment points (Figure 7), this suggests a high concentration of stress in that area. To mitigate the risk of future failures, some additional support could be added by increasing the size or wall thickness of the tubes or including a gusset to strengthen the welded connection to the caster barrel.

The noncritical caster bolt failures were due to the caster adjustment bolts being too small to support the load of the test dummy and wheelchair while traveling over the slats of the MDT. This could cause a sudden 


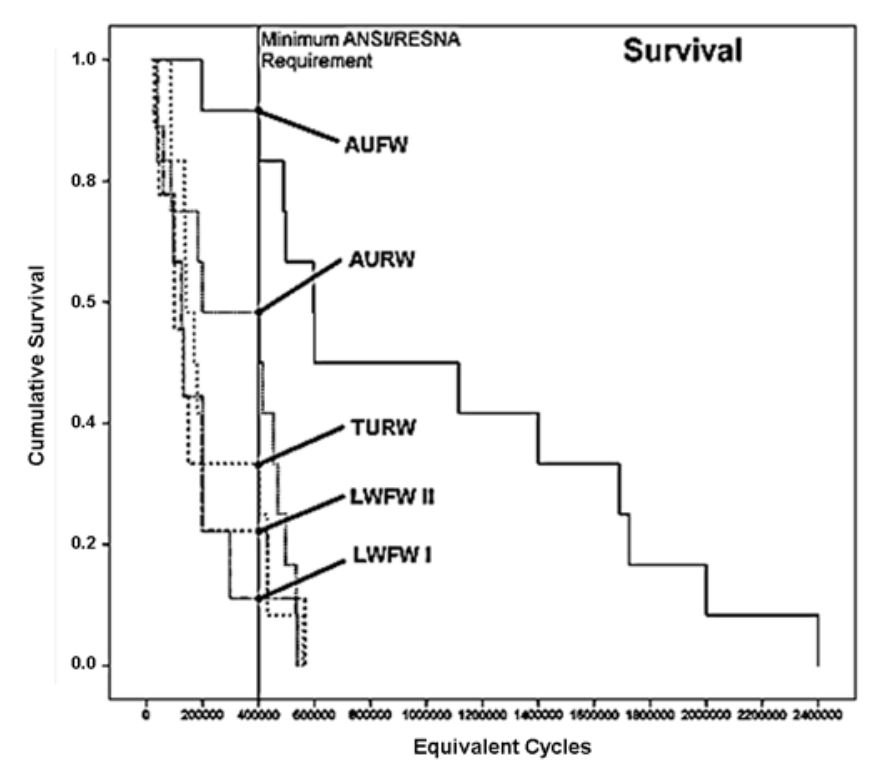

Figure 11.

Kaplan-Meier plot of equivalent cycles for current lightweight folding wheelchairs study (LWFW II) and four previous studies: lightweight folding wheelchairs I (LWFW I) [12], aluminum ultralight folding wheelchairs (AUFW) [13], titanium ultralight rigid wheelchairs (TURW) [14], and aluminum ultralight rigid wheelchairs (AURW) [15]. Note: Labels and leader lines show cumulative survival for each study at American National Standards Institute/Rehabilitation Engineering Society of North America (ANSI/RESNA) minimum equivalent cycles value.

shift in the balance of the wheelchair, resulting in similar hazards for an end user to those described in the critical failure case.

\section{Invacare Patriot Plus}

The rear upright failures that the Patriot Plus wheelchairs experienced in this study are likely due to a combination of the rigid, welded attachment of the upright to the main frame and weakness induced in the aluminum frame during welding. When evaluating the failure, we discovered a large weld mating the upright to the wheelchair frame. The heat required to create this weld could have potentially weakened the structure enough to cause the failure. No information is available from the manufacturer regarding the construction methods, specifically whether there was any postwelding heat treatment of the aluminum. If a postweld heat treatment is not performed, the aluminum in the fusion and heat-affected zones is left in a softer state than the unwelded sections, which makes it susceptible to failures like those seen in our testing [19]. This weakness can be accounted for without additional heat treatments by designing the welded joints so they will be strong enough to survive the operating loads in the postwelded state.

Only one of the Patriot Plus wheelchairs experienced a noncritical failure, but this was likely due to the early critical failures. The seat fabric bolts failed and caused the fabric to separate from the seat frame. This could also potentially cause an injury by allowing someone to fall down into the frame of the wheelchair or slide out and onto the ground.

\section{Invacare 9000XT}

The 9000XT was the only model tested that used carbon steel as a frame material. Despite this, the frame cracks still occurred near welded joints, indicating a similar type of failure to those seen in the other models we tested. Because of the thin-walled tubing used in construction, we could not analyze the fracture surfaces to positively determine the presence of a brittle failure. Another cause for concern discovered after the failures was corrosion inside the tubing of the wheelchair frames (Figure 9). While it is unlikely that this was the sole cause of the failures, it is possible that the corrosion contributed to the weakness of the structure or the welded joint.

The noncritical failures seen consisted of seat fabric bolt failures and a caster axle failure. The seat fabric failed on two of the three wheelchairs, and one experienced a caster bolt failure. As with the seat fabric failure seen in the Patriot Plus, this could cause a user to fall into the seat frame or to slide out of the wheelchair. The caster bolt failure would cause similar control issues to those described for the frame failure and separation of the 9000XT.

\section{Areas of Concern}

The results of this study show that the durability of wheelchairs in the lightweight category has remained stagnant over the past 15 yr. Furthermore, seven of the nine wheelchairs we tested did not meet the minimum durability requirements in the ANSI/RESNA standards. When compared with previous studies on ultralight wheelchairs, our results showed that the lightweight wheelchairs we tested performed significantly worse on the durability tests. 
Table 8.

Possible consequences for wheelchair user that may occur as result of wheelchair failures.

\begin{tabular}{ll}
\hline \multicolumn{1}{c}{ Failure Location } & \multicolumn{1}{c}{ Possible Consequences } \\
\hline Front Caster & $\begin{array}{l}\text { Forward tip and/or fall. } \\
\text { Stranded. }\end{array}$ \\
\hline Front Frame & $\begin{array}{l}\text { Forward tip and/or fall. } \\
\text { Caster may become damaged or sepa- } \\
\text { rate from wheelchair, stranding user. }\end{array}$ \\
\hline Rear Frame & $\begin{array}{l}\text { Main wheel may separate or become } \\
\text { jammed, causing tip or stranding user. }\end{array}$ \\
\hline Rear Seat Upright & $\begin{array}{l}\text { Users may fall backward, causing head } \\
\text { injury. May be unable to lift him- or } \\
\text { herself from this position. }\end{array}$ \\
\hline \hline
\end{tabular}

Another area of concern is the failure rate in the community. As previously mentioned, studies have shown failure rates as high as 52.8 percent over a 6 mo period, which when compared with our failure rates over an estimated 3-5 yr life cycle, indicates that our results may, in fact, be more optimistic than what wheelchair users are experiencing. A direct comparison of laboratory-based studies such as ours to the failures seen in the community would be very useful in the future to highlight how wheelchair testing results correlate with failures in the real world. Insight gained from such a study would assist the ANSI/RESNA wheelchair standards committee when updating the wheelchair testing standards to better address the shortcomings apparent in the real world.

\section{Methods for Improving Wheelchair Reliability}

The lack of an explicit minimum set of requirements for manual wheelchairs going through the $510(\mathrm{k})$ process or applying for CMS coding leaves an opening for "costreduction engineering," which has been observed in the wheelchair manufacturing industry [20]. This could contribute to the lack of quality and performance improvements observed during this study. Increasing the quality and performance requirements required by CMS for coding would be an excellent first step toward improving quality. If CMS required performance information, manufacturers would have to show that their wheelchair models met the minimum requirements by submitting test reports. Although CMS does require test reports for power wheelchairs, they do not require that the MDTs and CDTs be performed by an independent test laboratory. As this and other studies have shown, the performance of wheelchairs on these tests is lacking. If the test report requirement is expanded to include manual wheelchairs, these tests must be performed by an independent test laboratory to ensure that the results are not biased.

Another way to improve the safety and reliability of wheelchairs would be to require minimum performance results in order to approve them for sale in the United States. Currently, the FDA has an internal set of minimum requirements for approving $510(\mathrm{k})$ submissions; however, they have never been made public [21]. The FDA could significantly improve the quality of all wheelchairs by requiring performance information in the form of test results to determine whether or not a manual wheelchair is substantially equivalent to a predicate device. Since all wheelchairs must pass through the $510(\mathrm{k})$ process in order to be sold in the United States, this would mean that every model would have to meet a set of minimum standards. Meeting the minimum requirements alone is not sufficient to ensure the safety and reliability of the wheelchairs, however. With the current system, because there is no performance requirement, there is also no requirement for independent testing. As with the CMS test results, this increases the possibility of bias being introduced. To limit this risk, a requirement must be added that ensures the tests are performed at a third-party testing laboratory.

Yet another way to improve quality is to continue independently comparing wheelchair models at regular intervals and reporting the findings publicly. These studies provide valuable data for clinicians, insurers, and wheelchair users by uncovering problem areas and determining how a particular model compares with others. Again, the use of independent test laboratories is important not only to reduce the risk of bias, but also to ensure that the results are fully disclosed. With publicly available comparison information, wheelchairs that perform better will hopefully be prescribed more often, and therefore, the market will help to drive quality upward. Increasing the number of wheelchair models tested in each comparison study would help ensure that all common models have some available test data; however, this is cost prohibitive for independent test laboratories with limited funding.

One problem that arises in comparison studies such as this one is that even though the results are made public, comparing wheelchairs across different studies is time consuming and may not be possible for someone unfamiliar with the ANSI/RESNA wheelchair standards. To improve this situation, we have developed a simple rating system for wheelchairs (Table 9). The basis for our 
Table 9.

Proposed five-star rating system for wheelchairs and equivalent cycle results.

\begin{tabular}{|c|c|c|c|c|c|}
\hline & * & $* *$ & $* * *$ & $* * * *$ & $* * * * *$ \\
\hline Midpoint of Each Star Range Based on \pm SD & 54,663 & 227,332 & 400,000 & 572,668 & 745,337 \\
\hline Low Limit & 0 & 140,998 & 313,667 & 486,335 & 659,002 \\
\hline
\end{tabular}

model is the five-star rating system used by the NHTSA to rate automobiles. Including ratings on new wheelchairs provides an easy way to see how each model compares with others in its class. In the NHTSA system, a five-star rating means that the risk for injury in an accident is much less than average and the risk increases as the number of stars decreases [22].

To demonstrate our version of such a rating system, we took the mean equivalent cycle data from this study and rated the wheelchairs based on the results (Table 10). We used 400,000 equivalent cycles as the basis for a three-star rating and used SDs above and below for each rating level. Thus, a wheelchair completing 745,336 cycles (400,000 plus two SDs of 172,668 equivalent cycles) would receive a five-star rating. A wheelchair completing 54,664 cycles or below would receive a onestar rating. If this rating system is implemented, a method for incorporating user feedback should also be included. This would allow actual wheelchair users to rate their experience with a particular wheelchair. These data would be valuable not only because they would greatly increase the number of data points for determining quality, but also because they would provide results that are not limited to a laboratory setting.

This model would easily translate to the wheelchair industry; an information sheet could be attached to the wheelchair showing how it performs in durability tests compared with the average result. Stability and other performance data could also be rated to give a better picture of how each wheelchair compares. Ideally, this method

Table 10.

Proposed five-star rating system (Table 9) applied to mean equivalent cycle data from this study.

\begin{tabular}{lcc}
\hline \multicolumn{1}{c}{ Wheelchair } & $\begin{array}{c}\text { Equivalent } \\
\text { Cycles }\end{array}$ & Star \\
& Rating \\
\hline & 365,916 & $* * *$ \\
Invacare Patriot Plus & 68,174 & $*$ \\
Invacare 9000XT & 149,416 & $* *$ \\
\hline \hline
\end{tabular}

would complement the direct reporting of test results and not totally replace it. With both methods in place, it would be easy to quickly compare models yet still have all the data available for an in-depth analysis when necessary.

\section{Limitations}

A limitation of this study was the small sample size of wheelchairs compared. Three samples of three different wheelchair models were tested. Testing additional wheelchairs, as well as having more samples for each model, would improve the reliability of the data presented. The limiting factor for the sample size of this study was the high cost of purchasing the wheelchairs.

\section{CONCLUSIONS}

When a person is first prescribed a wheelchair as a mobility aid, it can be a daunting process to determine which model will best fit his or her needs. Decisions based on cost, fit, and style must be weighed to provide the best possible outcome for the wheelchair user. Our study found that despite improvements in design and manufacturing technology, wheelchair durability has not improved since the last time lightweight wheelchair offerings were compared. Many of the shortcomings found in the past still have yet to be addressed in today's models. Despite technological advancements in manufacturing and design, durability, stability, and braking effectiveness have not improved. This represents a lack of attention to this wheelchair category by the manufacturers. Durability results from ultralight wheelchairs prove that it is possible to create a wheelchair that can pass the ANSI/RESNA standard tests, but the lightweight category, unfortunately, is lagging behind.

All in all, our findings reveal some troubling trends in the wheelchair manufacturing industry. No minimum requirements, continual pressure to reduce costs, and a lack of CMS funding seem to result in a quality deficit for wheelchair users. Hopefully, improvements in manufacturing 
methods and revamped regulations will be implemented in the future to reign in trouble areas and ensure that wheelchair users are provided with the best possible product and, in turn, the highest quality of life they can attain.

\section{ACKNOWLEDGMENTS}

\author{
Author Contributions: \\ Study concept and design: B. Gebrosky, J. Pearlman, R. A. Cooper, \\ R. Cooper, A. Kelleher. \\ Analysis and interpretation of data: B. Gebrosky, J. Pearlman, \\ R. A. Cooper. \\ Drafting of manuscript: B. Gebrosky, J. Pearlman, R. A. Cooper. \\ Critical revision of manuscript for important intellectual content: \\ B. Gebrosky, J. Pearlman, R. A. Cooper, R. Cooper, A. Kelleher.
}

Financial Disclosures: The authors have declared that no competing interests exist.

Additional Contributions: Annmarie Kelleher is now also affiliated with the Department of Rehabilitation Science and Technology, University of Pittsburgh, Pittsburgh, Pennsylvania.

Funding/Support: This material was based on work supported by the Center for Excellence for Wheelchairs and Associated Rehabilitation Engineering (grant B6789C).

Disclaimer: The contents of this article do not represent the views of the VA or U.S. Government.

\section{REFERENCES}

1. Paralyzed Veterans of America Consortium for Spinal Cord Medicine. Preservation of upper limb function following spinal cord injury: A clinical practice guideline for healthcare professionals. J Spinal Cord Med. 2005;28(5):434-70. [PMID:16869091]

2. HCPCS. Health Care Financing Administration common procedure coding system, national Level II Medicare codes. Salt Lake City (UT): Med-Index Publications; 2012.

3. Boninger M. Repetitive strain injuries in manual wheelchair users. In: Woude LH, Hopman MT, Kemenade CH, editors. Biomedical aspects of manual wheelchair propulsion: A state of the art II. Lansdale (PA): IOS Press; 1999. p. 115-21.

4. ANSI/RESNA. American national standard for wheelchairs. Washington (DC): American National Standards Institute; 2009.

5. Kirby RL, Ackroyd-Stolarz SA, Brown MG, Kirkland SA, MacLeod DA. Wheelchair-related accidents caused by tips and falls among noninstitutionalized users of manually propelled wheelchairs in Nova Scotia. Am J Phys Med Rehabil. 1994;73(5):319-30. [PMID:7917161] http://dx.doi.org/10.1097/00002060-199409000-00004
6. Xiang H, Chany AM, Smith GA. Wheelchair related injuries treated in US emergency departments. Inj Prev. 2006; 12(1):8-11. [PMID:16461412]

http://dx.doi.org/10.1136/ip.2005.010033

7. Gaal RP, Rebholtz N, Hotchkiss RD, Pfaelzer PF. Wheelchair rider injuries: Causes and consequences for wheelchair design and selection. J Rehabil Res Dev. 1997; 34(1):58-71. [PMID:9021626]

8. Fitzgerald SG, Collins DM, Cooper RA, Tolerico M, Kelleher A, Hunt P, Martin S, Impink B, Cooper R. Issues in maintenance and repairs of wheelchairs: A pilot study. J Rehabil Res Dev. 2005;42(6):853-62. [PMID:16680622] http://dx.doi.org/10.1682/JRRD.2004.10.0130

9. McClure LA, Boninger ML, Oyster ML, Williams S, Houlihan B, Lieberman JA, Cooper RA. Wheelchair repairs, breakdown, and adverse consequences for people with traumatic spinal cord injury. Arch Phys Med Rehabil. 2009;90(12):2034-38. [PMID:19969165] http://dx.doi.org/10.1016/j.apmr.2009.07.020

10. Worobey L, Oyster M, Nemunaitis G, Cooper R, Boninger ML. Increases in wheelchair breakdowns, repairs, and adverse consequences for people with traumatic spinal cord injury. Am J Phys Med Rehabil. 2012;91(6):463-69. [PMID:22549473]

11. PDAC. Application and checklist for PDAC HCPCS coding verification request. Manual wheelchairs [Internet]. Fargo (ND): PDAC; 2010. Available from: https:// www.dmepdac.com/docs/review/manual_wheelchairs.pdf

12. Cooper RA, Gonzalez J, Lawrence B, Renschler A, Boninger ML, VanSickle DP; American National Standards Institute-Rehabilitation Engineering and Assistive Technology Society of North America. Performance of selected lightweight wheelchairs on ANSI/RESNA tests. Arch Phys Med Rehabil. 1997;78(10):1138-44. [PMID:9339166] http://dx.doi.org/10.1016/S0003-9993(97)90141-6

13. Cooper RA, Boninger ML, Rentschler A. Evaluation of selected ultralight manual wheelchairs using ANSI/ RESNA standards. Arch Phys Med Rehabil. 1999;80(4): 462-67. [PMID:10206612] http://dx.doi.org/10.1016/S0003-9993(99)90287-3

14. Liu HY, Cooper RA, Pearlman J, Cooper R, Connor S. Evaluation of titanium ultralight manual wheelchairs using ANSI/RESNA standards. J Rehabil Res Dev. 2008;45(9): 1251-67. [PMID:19319751] http://dx.doi.org/10.1682/JRRD.2007.12.0204

15. Liu HY, Pearlman J, Cooper R, Hong EK, Wang H, Salatin B, Cooper RA. Evaluation of aluminum ultralight rigid wheelchairs versus other ultralight wheelchairs using ANSI/RESNA standards. J Rehabil Res Dev. 2010;47(5): 441-55. [PMID:20803388] http://dx.doi.org/10.1682/JRRD.2009.08.0137 
16. Cooper RA, Robertson RN, Lawrence B, Heil T, Albright SJ, VanSickle DP, Gonzalez J. Life-cycle analysis of depot versus rehabilitation manual wheelchairs. J Rehabil Res Dev. 1996;33(1):45-55. [PMID:8868417]

17. Cooper RA. Wheelchairs and related technology for the millennium. J Rehabil Res Dev. 2000;37(3):xiii-xvi. [PMID:10917256]

18. Americans with Disabilities Act (ADA) accessibility guidelines for buildings and facilities; play areas. Architectural and Transportation Barriers Compliance Board. Final rule. Fed Regist. 2000;65(202):62498-529. [PMID:11503682]

19. Pickett A, Fouinneteav M, Gudgeon S, Robin V, Christlein J. Model characterization and failure analysis of welded aluminum components including process history. Int J Crashworthiness. 2007;12(5):449-63.

20. Cooper RA. Engineering manual and electric powered wheelchairs. Crit Rev Biomed Eng. 1999;27(1-2):27-73. [PMID:10638849] http://dx.doi.org/10.1615/CritRevBiomedEng.v27.i1-2.20

21. U.S. Food and Drug Administration. Premarket notification 510(k) [Internet]. Silver Spring (MD): FDA; 2010. Available from: http://www.fda.gov/MedicalDevices/DeviceRegulationandGuidance/HowtoMarketYourDevice/

\section{PremarketSubmissions/PremarketNotification510k/} default.htm

22. National Highway Traffic Safety Administration. Toolkit for dealers and manufacturers [Internet]. Washington (DC): NHTSA. Available from: http://www.safercar.gov/staticfiles/toolkit/vm toolkit factsheets.htm

Submitted for publication August 23, 2012. Accepted in revised form June 13, 2013.

This article and any supplementary material should be cited as follows:

Gebrosky B, Pearlman J, Cooper RA, Cooper R, Kelleher A. Evaluation of lightweight wheelchairs using ANSI/ RESNA testing standards. J Rehabil Res Dev. 2013; 50(10):1373-90.

http://dx.doi.org/10.1682/JRRD.2012.08.0155

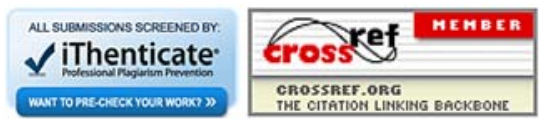

